\title{
"En mi hay algo que provoca reacciones adversas": Viñetas clínicas que ejemplifican el proceso de la psicodinámica cíclica en un paciente ${ }^{1}$
}

\author{
Lucía Blanco ${ }^{2}$ \\ IARPP-España
}

Esta presentación clínica expuesta en la VII Reunión anual de IARPP - E en Barcelona, está basada en un tratamiento psicoterapéutico que se enmarca en el paradigma de la TERAPIA PSICODINÁMICA CÍCLICA CONTEXTUAL aportado por Wachtel. A través de algunas viñetas clínicas podrá observarse cómo el paciente persiste tenazmente en viejas formas de captar y responder a ciertos contextos, organizando modos de conducta en forma de círculos viciosos que se retroalimentan, y que forman un patrón relacional de comportamiento, el cual da lugar a una psicodinámica cíclica, con la que renueva una y otra vez su experiencia de dolor y frustración. Mostrar este caso clínico es una contribución a la eficacia que ha tenido este modelo en la evolución del paciente. Se ofrecen nuevas alternativas y posibilidades encontradas en las sesiones clínicas, en las que se partirá siempre de aspectos actuales de su vida diaria, para centrarnos en conocer cuáles son sus modos de reaccionar, qué componentes le llevan a esas conductas y el valor causal de esos conflictos en su infancia temprana. No se perderá de vista que para producir avances y cambios, los dos, paciente y terapeuta formando una "terceridad", al decir de Jessica Benjamin, co-crearán poner una atención especial a los procesos subjetivos que vayan apareciendo en los sucesos narrados.

Palabras clave: Psicodinámica cíclica, patrón relacional, acomodación patológica, conexión emocional, "terceridad".

This clinical presentation was given at the 7th Annual Meeting of IARPP-E in Barcelona. It is based on a psychotherapy framed within the paradigm of Paul Wachtel's CONTEXTUAL CYCLIC PSYCHODYNAMIC THERAPY. Illustrated through several clinical vignettes, the patient can be seen persisting in longstanding ways of perceiving and responding to certain contexts, organising modes of behaviour in the form of vicious circles, and forming a relational pattern of behaviour which results in a cyclical psychodynamic. This reawakens his experience of pain and frustration time and time again. The clinical case demonstrates the effectiveness that this model has had on the patient's outcome. New alternatives and possibilities are identified in the sessions with the patient. The starting point, following Wachtel, is the current features in the patient's daily life, then focus is put on determining his ways of reacting, which components lead him to these ways of reacting, and the causes of these conflicts in early childhood. For there to be progress and change, both patient and therapist form a "thirdness" in the terminology of Jessica Benjamin; both participants give special attention to the subjective processes that emerge in the events recounted.

Key Words: Cyclical psychodynamics, relational pattern, pathological accommodation, emotional connection, "thirdness".

English Title: "There is something in me that causes adverse reactions": Clinical vignettes that exemplify the process of cyclic psychodynamics in a patient.

Cita bibliográfica / Reference citation: Blanco, L. (2017). En mi hay algo que provoca reacciones adversas. Clínica e Investigación Relacional, 11 (3): 508-523. [ISSN 1988-2939] [Recuperado de www.ceir.info ] DOI: 10.21110/19882939.2017.110302

\footnotetext{
${ }^{1}$ Trabajo presentado en la reunión bienal de IARPP-España, celebrada en Barcelona, Abril 2017

2 Psicóloga psicoterapeuta relacional, presencial y online. Directora del Centro Sanitario: "Consulta de Ayuda Psicológica Lucía Blanco", situado en Madrid. Titulada EUROPSY -(Federación Europea de Asociaciones de Psicólogos). ESPECIALISTA UNIVERSITARIA EN CLÍNICA Y PSICOTERAPIA PSICOANALITICA. Universidad Pontificia Comillas de Madrid en colaboración con la Escuela de Libre Enseñanza del Psicoanálisis (ELIPSIS). Perteneciente al Colegio Oficial de Psicólogos de Madrid desde 1981, a la Sociedad FORUM de Psicoterapia Psicoanalítica, y a IARPP. Vocal de la Junta Directiva de IARPP- España. Contacto: blancorejas@gmail.com
}

CelR Vol. 11 (3) - Octubre 2017 ISSN 1988-2939 - www.ceir.info

(c) Derechos reservados/Copyright de Clínica e investigación Relacional y los autores. Prohibida la reproducción total o parcial sin autorización expresa. Este material es para uso científico y profesional exclusivamente y puede contener información clínica sensible. Los editores no se responsabilizan de los contenidos de los autores. Dirigir las consultas sobre derechos y autorizaciones a ceir@psicoterapiarelacional.es 


\section{VIÑETA 1. UNA URGENCIA CAMINO DE GRANADA}

Verano 2016. Voy de vacaciones camino de Granada. Me llama por teléfono urgente una amiga. Me pregunta si estoy en España. Menos mal, dice, necesito una terapeuta online para un paciente que pide con mucha urgencia ser visto. Está muy deprimido. Yo argumento que voy a los Festivales de Música y Danza de Granada y por tanto pasaré cuatro días fuera de la consulta. Me pide por favor que lo atienda. Estoy de viaje, le digo, dile que el próximo lunes me llame. Esa misma tarde llama el paciente agobiado que, por favor, necesita hablar con una terapeuta online, que se tiene que ir a trabajar fuera de España y le urge mucho. Ante su vehemencia y el de mi amiga, a mi se me dispara mi lado débil. Y accedo. Hablo con el gerente del hotel que es amigo mío y me proporciona un despacho con wifi para poder atender a mi paciente.

Todo este preámbulo es para ver alguna de las características de A.: su impulsividad, su vehemencia, su necesidad imperiosa de que las cosas se hagan cómo y cuando él las demanda. También su capacidad de gestión, (referida ésta sobre todo a cómo nos puso a todos en acción).

Mientras escribo esto se me ocurre la idea de que si yo en lugar de vivirlo como una muestra de su capacidad para implicarme y para gestionar, lo viviera como que es un controlador dominante, seguramente las cosas hubieran seguido un curso distinto. Quizá es un buen ejemplo de que los terapeutas no somos neutrales y que cada uno vive la misma situación de manera distinta. (Wallin)

Cuenta el paciente que está sin motivación y que necesita relajarse antes de volver de vacaciones al Chad (trabaja como asesor-gestor en la construcción de hospitales internacionales). Que está muy, muy deprimido y que el desencadenante de su angustia y de su urgencia ha sido que su pareja hace 5 días que le ha dejado. Y añade algo que va a ser importante para comprender después su dinámica cíclica "Te confieso que no sé lo que me pasa, pero últimamente noto que es como si tratase de forzar la pérdida de las parejas. Y lo mismo me pasa en el trabajo, es como si provocase que las situaciones se rompan, porque no las conduzco a una salida lógica. Necesito que me ayudes a asimilar lo que ha pasado, a estabilizar la situación que vivo ahora. Y también a trabajar las raíces de esto, porque no es algo puntual, sino que hace tiempo que me acompaña y no sé de dónde viene." Esto confirma la idea de Wachtel cuando describe cómo nuestra conducta está en relación con el contexto de los acontecimientos que vivimos, y cómo nuestra respuesta depende no sólo de lo que ocurre en ese contexto, sino de la interpretación subjetiva de esos acontecimientos.

Ahora después de unos meses de psicoterapia, puedo vislumbrar lo reactivo que es a los acontecimientos que ocurren a su alrededor y su vulnerabilidad a cualquier fallo empático 
por parte de su entorno. Y en esos momentos de vulnerabilidad y reactividad, una mujer y la sexualidad son como un clavo ardiendo al que se coge desesperadamente como ultimo agarre para no caer en el abismo. (Raimundo Guerra) El problema es que cualquier tensión con la chica, no le sirve de agarre y se siente soltado en medio del abismo. Esta es la situación en que está cuando viene a la consulta: le urge tanto, está mal porque una chica le ha tirado al abismo.

Relaciono esto con la urgencia de su llamada y no poder esperar, con cómo de pequeño no hubo unas figuras de apego que calmaran, y él estuvo obligado a calmarse solo y de forma rápida. "Si, eso me pasa en el trabajo y en la relaciones, necesito que las cosas sean ya, no tengo paciencia para esperar, soy impulsivo, no valoro pros y contras, nunca he sido apoyado, tengo la sensación de ser yo el que ha de tomar decisiones y saber cómo he de moverme, en muchas de las gestiones que hago." Como dice Bowlby, al no contar con una historia de apego seguro, las crisis constituyeron un reto mayor porque su capacidad adaptativa para las relaciones fue más débil.

\section{VIÑETA 2.- "ADMIRABA A MI PADRE A PESAR DE SU EDUCACIÓN VICTORIANA"}

"De mi infancia temprana apenas tengo recuerdos (llanto). Es como asomarse al abismo, como un agujero negro al que me da miedo caerme, me asusta mucho".

El tema del agujero negro es una herida horrible donde queda penetrado de un llanto profundo que desgarra y sobrecoge. En esos momentos, que han sido muchos, le digo que ahora estamos los dos para asomarnos juntos a ese abismo, que no está solo, que yo no siento el miedo que siente él y que no va a pasar nada si vamos haciendo poquito a poquito algunos recorridos por su infancia. Yo le voy transmitiendo cómo de intensas son sus emociones cuando es escuchado y puede hablar. (S. Buechler). Y es no sólo poder percibirlo y escucharle cuando llora, sino validarle ese llanto, incluso sin palabras, acompañándole en esa conexión emocional de: "Tu sientes que yo siento lo que tu sientes". (R. Riera ) Y empieza a contar hechos verdaderamente escalofriantes. "Yo tenia miedo a la oscuridad, a la casa, al despacho de mi padre con la puerta cerrada, él siempre estaba dentro y no con nosotros. Yo siempre estaba esperando a su puerta a que saliera para que jugáramos, algunas veces lo hacía y me gustaba. Pero él era el poli malo, el que tenía que reñir. Siempre oía a mi madre: "le voy a decir a tu padre", "cuidado con papá". (llanto que sobrecoge). Yo lo admiraba y lo quería, era el referente, pero la amenaza de mi madre era real, el carácter de mi padre era horrible. Una vez hizo limonada, yo le quise ayudar y dije que le hacía falta más azúcar y lo eché, y mi padre decía que no hacía falta tanto que estaba muy dulce, pero a míme pareció que hacía falta más y seguí echando, asi que vino y me echó la limonada por la cabeza. Tenía modales que eran más 
victorianos que violentos. Sobre todo, buscaba siempre el buen comportamiento, buenos resultados, rectitud y que fuéramos muy valientes. Con esa edad, 6 años, yo robaba cosas en el cole a los compañeros. Unas navidades en casa de unos amigos de mis padres yo me llevé un juguete de su hijo. Cuando se descubrió, mi padre me llevó a que devolviese el juguete en la casa (que sentimientos de vergüenza, de rabia, de miedo tendría A.) y de ahí ¡me llevó a la cárcel de mi ciudad! (qué terror recorrería su cuerpo). En ese momento creí que me dejaba dentro, fue horrible. Todo era en esa línea".

¿Os imagináis como estaba yo cuando le oía contar todas estas cosas y algunas más del mismo calibre? Me imaginaba a un niño que ha cogido algo para cambiarlo con otro compañero por dinero y poder comprarse unos cromos o unas chuches, y acaba en que le van a meter en la cárcel. En esa situación el niño no piensa que le quieren mostrar cómo acaban los ladrones, sino que lo único que siente es que acabará ahí de verdad. Él me dijo que había estado seguro de que su padre le dejaría en la prisión.

En él fue quedando incrustado como patrón relacional "todo lo que toco lo rompo, no se gestionar bien". (D. Orange y S. Doctors). Esto lo repite muchas veces, es la etiqueta que lleva desde su infancia. Y con eso además de una mortificación, lo que hace es darle la razón a su padre: "mira lo desastre que eres, mira como acabas mal". Ante eso yo le digo de muchas formas y con ejemplos concretos: "iNO!, tu has hecho cosas muy brillantes que tu padre no ha sabido reconocerte, por ejemplo la gestión que hiciste brillantemente de tantos millones de dólares y lo unidos que estáis tu hija y tu... y tantas otras cosas que podemos nombrar. ¡Qué es eso de que todo lo has hecho fatal!. Así yo me convierto en alguien que no le confirma la idea machacante y las auto-mortificaciones que haya aprendido de su padre.

"Mi madre jugaba el papel de poli buena. No creo que la viese como mala, te acusaba al padre, pero no era el ogro que podía venir, me sentía protegido por ella". Eso decía al principio de comenzar las sesiones, pero ahora que está más acostumbrado a abrir su mente y reflexionar, dice de ella: "Ahora sé porqué me cuesta mucho ver a mi madre. Ahora siento que en verdad no hubo ese cuidado ni esa protección, solo fue en la superficie. Tengo la visión de que se preocupa más por ella que por nadie y hace las cosas de una forma que todo el mundo esté pendiente de lo mal que está ella. Trata de hacer muchas cosas para reprocharnos lo que no hacemos, y verla supone mucho esfuerzo. Cuando estoy muy bien voy a verla, pero a las dos horas me quedo sin energía. Tengo miedo a que se me contagie su victimismo, esa idea que tiene de que el mundo está contra ella". Cuando me cuenta esto después de que han pasado unos meses de terapia, pienso en lo que dice Wachtel: "El cambio es el proceso, y lo que se descubre no es algo que ya estaba ahí, sino algo que surge del propio proceso de exploración e interacción en sí mismo".

\section{CeIR Vol. 11 (3) - Octubre 2017 ISSN 1988-2939-www.ceir.info}

(c) Derechos reservados/Copyright de Clínica e investigación Relacional y los autores. Prohibida la reproducción total o parcial sin autorización expresa. Este material es para uso científico y profesional exclusivamente y puede contener información clínica sensible. Los editores no se responsabilizan de los contenidos de los autores. Dirigir las consultas sobre derechos y autorizaciones a ceir@psicoterapiarelacional.es 


\section{VIÑETA 3.- EN EL COLEGIO FUE CASI LA NORMA QUE ME ECHARAN DE LA CLASE DESDE QUE EMPEZABA}

Cuenta que en el colegio tuvo unos profesores, y especialmente el profesor de inglés, que fueron muy represivos, que le acusaban muchas veces de estar distraído en clase, de hablar, asi que la forma que tenían de solucionarlo era echarle de la clase al poco de empezar. "Pero nunca me enseñaron cómo mejorar. (Fuerte llanto). Echarme de la clase era doloroso porque yo asumía lo que me decían, "que era un fracaso, que mejor que buscara un trabajo,... y sólo tenia 14 años. Yo hubiera necesitado de mis profesores que fuesen más persona, veía que con otros chicos se comportaban de otra forma, independientemente del rendimiento académico. En las actividades deportivas nunca me elegían para formar parte de la selección de futbol, siempre me dejaban el último o en el banquillo porque decían que era torpe, muy malo, que si estaba dormido.

Resultado de todo aquel infierno es que logró terminar con muchas dificultades la E.G.B. y alguno curso de bachillerato. Es de mayor cuando ha hecho una gran formación para conseguir el buen perfil que tiene y poder llegar a donde quería. "Creo que aprendía marcar mis propios caminos para escapar de ese mensaje de fracaso que siempre escuché. "En aquellos momentos yo era muy sensible a ciertas reacciones contra mi, y no tenía recursos". (llanto fuerte). Yo le comento que he trabajado muchos años en el mundo de la educación y sé bien lo significa repetir curso y que le echaran permanentemente de la clase. $Y$ admiro que a pesar de eso se empeñase en estudiar cuando fue mayor porque supone un gran esfuerzo y mucho tesón, y tiene un inmenso valor. (Vygotsky), "Si, lo sé, pero me queda una huella de no sé qué, me sale ese sentimiento de lo que no hice, de no tener un titulo universitario (a pesar de tener varios cursos de experto universitario). Mi mundo es competitivo porque la gente tiene mucha preparación para estar en puestos de responsabilidad. Pero en mi curriculum... pesa más la experiencia que lo académico.

El suyo fue el PATRÓN RELACIONAL de un niño con una historia significativa de conflictos parentales y escolares, cuyos apegos fueron desbaratados y su sentido de seguridad socavado. Todo ello conformó una representación de si como inferior, siempre en una búsqueda sedienta de ser reconocido, de sentirse abandonado, impotente y rabioso. Pensando en que las experiencias traumáticas tempranas establecen alertas relacionales tempranas, a A. en momentos de dificultad se le activan esas experiencias tempranas e interactúa con ellas. Esta idea me hace conectar con lo que le he oído en muchas ocasiones a Rosa Velasco acerca del impacto que en pacientes produce una detención en el desarrollo emocional. $Y$ conecto con Wachtel cuando afirma que aunque estos patrones son persistentes, sin embargo hay una enorme variabilidad en el estado interno y en el 
comportamiento de la persona dependiendo de la situación, de las personas con quienes esté. Efectivamente creo que es fundamental para el terapeuta entender esto.

También quiero resaltar la figura del profesor de inglés como alguien que según cuenta, influyó notablemente en su infancia y que dejó en él una poso de experiencias traumáticas que le mantuvieron y le siguen manteniendo en estado de alerta contínua, y en según que contextos relacionales se le activan esas experiencias tempranas e interactúa con ellas. De ese profesor dice: "fue un mal hombre (llanto fuerte que interrumpe lo que hablaba), ahora he conseguido saber inglés, pero me dejó heridas muy profundas. Recuerdo sus comentarios de que yo era un desastre, ¡cómo me humillaba siempre públicamente!. Él fue un maltratador para mi aunque no me pegara. (Llanto). (Hugo Bleichmar). Y lo mismo hizo en contra de mi hermana. Siempre he pensado que él con tanto maltrato, fuera el causante de que mi hermana terminara tan mal y que, con 13 años se metiera en el mundo de las drogas, con los problemas que eso supuso, y que terminara muerta por una sobredosis. Su muerte me afectó mucho y no solo por la muerte, sino por la historia que vivimos con ella. Aprendimos que cualquier día podía pasar que se muriera, y cuando ocurrió fue constatar el fracaso que había sido su situación, (llanto fuerte). Me causa mucha tristeza contarte esta historia, Lucía.

En su relato aparece cómo este chico tiene clara la influencia del colegio y sobre todo del profesor de inglés. El tema de la muerte de la hermana y de cómo en su imaginario quedó esta muerte, la drogadicción, los conflictos, es algo muy potente Por eso él se siente muy triste cada vez que hablamos de esto. Y por eso es comprensible cuando dice que "hay en mi una parte emocional no asentada, que provoca reacciones adversas. Esa parte emocional es a la que más miedo tengo porque me perturba".

Probablemente cuando él llegaba a casa y contaba los desprecios, las humillaciones, las descalificaciones del profe de inglés, no se encontraba con una mirada que dijera: entiendo el dolor que tienes, sino todo lo contrario, le dirían: ¡algo habrás hecho tu!, ¡si te portaras mejor!, ¡si fueras buen chico!. O se encontraba con la indiferencia, como cuando repite: "yo decía a mis padres que nos cambiaran de colegio, pero ellos no tenían tiempo para nosotros". No lo registraron como algo relevante, sólo se dieron cuenta del ambiente hostil del colegio cuando vieron los estragos de la droga en la hermana. Con la 3 a hija cambiaron las cosas. Por eso mi manera de escuchar, de validar el sufrimiento por un lado y de reconocer sus capacidades por otro, y hacerlo de forma auténtica y espontánea, han tenido un efecto de balsámico para las heridas de su infancia (Blanco, L y Riera, R.)

Cuando A. fue contando sus experiencias infantiles, así como lo que había narrado en su motivo de consulta y algunas escenas que detallaré en otras viñetas, me hizo pensar en la teoría que había conocido tiempo antes, de la psicodinámica cíclica: "La persona tiende a 
comportarse de formas repetitivas, e inducir a que los demás se comporten de forma que mantengan un determinado patrón interaccional". (Wachtel) En A. es claro como su patrón relacional se pone en acción.

En el colegio cuando se sentía humillado por el profesor de inglés, contestaría hasta que le echaran de la clase, o se pegaba con los compañeros hasta romperse la muñeca, o les robaba cosas. (hechos reales que él comentó)

Ahora en contextos autoritarios o que minusvaloran $\rightarrow$ se defiende atacando $\rightarrow$ le desprecian al ver que ataca $\rightarrow$ él se siente mas humillado $\rightarrow$ realimenta su patrón relacional: soy un desastre, no lo haré bien, provocaré reacciones adversas.

En contextos donde no se siente a la altura $\rightarrow$ se bloquea $\rightarrow$ se retrae $\rightarrow$ no colabora $\rightarrow$ los otros le acaban diciendo que no está a la altura y que no juega en equipo

Es decir, en cuanto nota un atisbo de malestar, eclosiona, y por la angustia, ese atisbo se convierte en fatalidad.

\section{VIÑETA 4.- EL WORKSHOP Y LA ACTIVACIÓN DE LA DINÁMICA CÍCLICA}

Está en un nuevo trabajo en Somalia desde hace dos meses y le han mandado a hacer un taller de coordinadores de proyectos, donde dice que se siente raro, como fuera de sitio al estar con gente de mucho nivel, y que su nivel de inglés no es muy bueno y le cuesta seguir.

NARRATIVA DE CÓMO COMIENZA UNA ESPIRAL DINÁMICA "Hoy en el taller he estado al principio concentrado y bien, pero luego al ver que mi nivel no es tan fuerte como el de ellos, empecé con la dinámica de: "no lo sé hacer, no tengo cultura, me preguntarán y no lo entenderé. Ya noto que me empiezo a echar para atrás tratando de escaparme y de pasar inadvertido. . Y como estoy dando vueltas a esto, no escucho y no me entero. Es verdad que si le diera otro enfoque estaría más motivado y me saldría mejor. Este es el mecanismo automático de provocar que las cosas se caigan y me da mucho miedo."

Y a continuación señala algo importante, donde aparece claramente cómo su inseguridad le lleva a que se active su patrón relacional de no sentirse a la altura: "Y no es sólo lo del taller sino también me pasa que tengo que entregar unos documentos a mi jefe, que no son difíciles de hacer, pero los estoy retrasando por lo mismo, porque me digo: lo vas a hacer mal, no estas a la altura, no vales para esto, te van a echar. Noto que ya estoy moviéndome cuesta abajo, me anticipo negativamente a cómo van a ir las cosas, me doy cuenta de que no es lo que me digan, sino lo que yo pienso que ellos piensan, y doy por seguro que me van a suceder tal como las imagino, es como una profecía autocumplida". Esto es lo que Wachtel llama los bucles cíclicos. 
" $Y$ desde hace 5-6- años estoy con el mismo miedo que tengo esta semana. Con mi equipo estoy muy bien, son casi 40 personas a mi cargo, me están saliendo bien los inicios y eso a nivel personal me llena. Pero es que mi profesor, que es mi jefe, me tiene que evaluar. $Y$ es un tipo de persona como las que han ido apareciendo a lo largo de mi vida y que representan figuras que están por encima de mi, que son autoritarias, nada dialogantes y no sólo no reconocen sino que además critican. Tras reflexionar juntos sobre su pasado y su presente, dice: "justo, me recuerda a como era mi profesor de inglés y como fue mi padre. Y en esas situaciones yo por dentro me rebelo. ¡Aun no he llegado a ese punto, pero es como si lo viese venir!". Parece que el jefe le ha señalado algunos puntos, que A. ve positivos, pero eso mismo le ha asustado y empieza funcionar su patrón relacional: "pienso que no valdrá lo que hago, siento miedo, retardo el entregarlos, y el jefe me los vuelve a pedir. No estoy enfocando bien las cosas, al revés estoy creando una relación desviada, que no tiene que ver nada con lo que quiero. Y me entra el miedo de que "me echen como en el colegio" y vuelva a sentirme humillado.

En otro momento hablando sobre cómo le ha ido en el taller, tiene un relato que es muy esperanzador y es donde yo empiezo a ver la identidad nueva que está apareciendo, su nueva subjetividad. Se me hace claro lo eficaz que está siendo para A. que en las sesiones sigamos las pistas que nos da esta teoría de la psicodinámica cíclica: "También te diré que hoy he visto una fuerza que tiraba hacia el no y otra que me decía que tenía que contribuir, jugar en equipo. Me acordé de las conversaciones que tuvimos sobre estos temas, del bucle en el que me meto, que no soluciono nada y sin embargo salgo mal parado. Asi que me crecí y quise empeñarme en pertenecer a la "selección". Y en una reunión me animé y me dije por dentro: "suelta lo que sabes, exprésalo, muévete hombre, que estás paralizado, piensa que tu tienes mucha experiencia, que conoces muy bien estas situaciones, que llevas muchos años siendo especialista en resolver dificultades, intenta darte a conocer en tu faceta mejor. Así lo hice y tras eso me animé y tuve algunas intervenciones que fueron valoradas muy positivamente. Esto ha sido muy importante. Incluso hice una exposición que generó un largo e interesante debate. "Estoy esperanzado Lucía, veo el comienzo de un nuevo camino". Llanto fuerte. Ahora contigo lo puedo valorar, pero es verdad que me pesa más lo negativo que lo que hice bien, esto último pasa a ser un valor residual.

Quiero comentar varias cosas a lo largo de esta viñeta,

1.- Dice: Ahora contigo lo puedo valorar ". Antes de que pasara sin más a otro tema, yo le hago pararse a que reflexionemos en el proceso seguido hasta llegar ahí. Y los dos fuimos co-construyendo una narrativa. Deseo enfatizar con esto la función terapéutica, la importancia de que A. vea estos bucles suyos, que de otra manera hubieran quedado como lo que Donell Stern Ilama "la experiencia no formulada". Concedí importancia a que lo 
habláramos en la sesión para que quedara explicitado, para que se le hiciera evidente y quedara ordenado en su cabeza "Ahora cuando me oigo decir eso que te estoy contando, me siento con capacidad de revertir la situación y al darme cuenta de esto será bueno que instalemos mecanismos automáticos, contrarios a ese bucle que formo". Que es lo mismo que decirme: voy a cambiar mi memoria implícita que me hace meterme en bucles automáticos y asi, a través de nuestras reflexiones, esta memoria implícita quedará cambiada y podré reaccionar automáticamente de forma distinta.

Comentaba Ramón Riera lo importante de esa percepción mía de su valor, de sus recursos, de su capacidad organizativa. Y cómo esa admiración y valoración espontánea, junto al contraste entre lo que veo yo de él y lo que ve él de si mismo, es como un corriente de oxígeno puro directo a su self. Eso tiene un efecto nutriente que va reparando las heridas de su infancia. Y que la teoría de los dinámica cíclica es muy potente para ordenar el caos de este hombre, pero que lo que genera el cambio psíquico es mi resonancia emocional, mi conexión emocional con él.

2.- Él está ahora en un entorno muy nuevo, es un entorno extraño, con personas desconocidas, teniendo que usar una lengua en la que no se siente ágil, el inglés, (¡el inglés y el profesor de inglés!,). En esta viñeta es muy interesante señalar que no es que él proyecte la realidad del colegio de su infancia en este contexto del workshop, sino que el contexto que vive ahora en el workshop es una réplica muy exacta de cómo se sintió de niño, en un sitio muy extraño, con unos adultos que no conocía de nada, donde se hablaba un lenguaje de adulto con el que él no estaba familiarizado, donde no había afecto, lo único que había era sentarse en el pupitre, escribir y echarle de la clase. Y ahora se le reactivan aquellas antiguas sensaciones.

Todo esto lo podemos ver de dos maneras que incluso parecería que dijeran lo mismo:

a).- él proyecta el colegio de su infancia en el workshop que está haciendo en Somalia.

b).- en el workshop que está haciendo en Somalia, lo traumático de estar trabajando en un país en guerra, que puede ser peligroso y amenazante, le hace revivir lo traumático del colegio de su infancia.

Aparentemente parecen lo mismo, pero tal como Wachtel explica en el libro La Comunicación Terapéutica, dependiendo de las palabras que cada persona utiliza se transmiten unos matices muy distintos. Así es muy distinto decir: "tu arrastras una tara y todo lo ves negro porque estás tarado desde tu infancia" (opción a), a decir: "la sensibilidad que tu adquiriste en tu infancia te hace ahora vivir las cosas de determinada manera, lo cual a veces es bueno porque entonces te hizo que te sublevaras, pero a veces es malo porque ves 
amenazas donde no las hay. (opción b). Esa apreciación supone que en la sesión clínica hay un cambio de matiz que es central, es decirle: "qué valioso es que tu, A. puedas estar en este entorno tan complicado y desenvolverte bien en él, y más teniendo en cuenta que tu ya vienes de un sitio en el que lo pasaste muy mal, con un entorno muy similar."

Es decir, en vez de poner el énfasis en que él arrastra una tara de su infancia que le impide desenvolverse en un contexto en el que cualquier otro se desenvolvería bien, por ejemplo alguien que hablara ingles mejor que él, en lugar de poner el énfasis en eso, lo que se dio en la sesión fue decirle: "qué mérito tienes, qué valioso es todo lo que haces, y más teniendo en cuenta la mochila que tu ya llevas de tu pasado. Y ahora vamos a trabajar mucho para cuando esta mochila te complique las cosas". Y siempre con la finalidad de que pueda tener conciencia de los recursos que él tiene con los cuales pudo sobrevivir a una situación muy traumática, de la cual su hermana no sobrevivió. A este respecto dice: "Es verdad, fue lo mismo para los dos: los mismos padres, el mismo colegio, el mismo barrio, cada uno corrimos en dirección distinta. Mi hermana corrió en una dirección y yo en otra, ella se destruyó y yo viendo su destrucción me fui por un camino totalmente opuesto y pude asimilar otras formas de vivir, pero me quedó esa fuerza destructiva de lo emocional".

3.- Quiero comentar con todos algo que ocurrió cuando yo preparaba esta comunicación. Justo el día antes de hacer el resumen de esta presentación para entregar al comité científico, el paciente me contó en la sesión esta viñeta. Creo que me dio el ejemplo mas claro de lo que yo quería presentar. Asi que según escribo esto se me ocurre una pregunta ¿incluir esto fue una casualidad? ¿O es que la neutralidad del analista no existe y que los intereses del analista co-construyen la relación? (J. Benjamin). No es que el paciente viene con su pasado como se creía antes en el modelo one person. No es que él viene y yo que soy muy neutral pienso que él me aporta las cosas que están como selladas en su self arcaico. No, lo que sí ocurre es que el terapeuta también co-construye de forma bipersonal y bidireccionalmente. Esto es lo que Wachtel afirma cuando habla de la psicología bipersonal. Yo no soy una observadora estática y objetiva de lo que emerja del interior de A. Es más, si yo no estuviera tan metida en el tema de la psicodinámica cíclica quizá me hubieran pasado desapercibidos ciertos matices. Eso me lleva a participar en su idea de que si bien los patrones relacionales persisten a lo largo de la vida, también es cierto que desde el comienzo de la terapia hasta ahora, han podido observarse variaciones en el mundo interno de $A_{\text {., }}$ en sus representaciones, en sus deseos y en su comportamiento, en su capacidad de entender los distintos procesos que han ido apareciendo en las distintas situaciones. Además, y viendo el cambio que en pocos meses se ha ido produciendo en él, doy la razón a Wachtel cuando afirma "que el mundo interno del paciente no está congelado a nivel evolutivo en la primera 
infancia y desconectado de la experiencia del día a día, sino que se sigue reproduciendo en los diferentes contextos relacionales a lo largo de la vida del individuo.

\section{VIÑETA 5.- "CAMBIO DE DESTINO: A TRABAJAR EN PRIMERA LÍNEA DE GUERRA SI O SI. LA ESPIRAL CÍCLICA SE PONE DE NUEVO EN MOVIMIENTO}

1.- A poco de llegar y estar asentándose en su tarea, le destinan a otro sitio. Eso le ha contrariado. Y atención: Su preocupación no es el sitio a donde le envían, a una ciudad que está en primera línea de guerra, sino que su preocupación es que le han comunicado el cambio de forma autoritaria y sin posibilidad de diálogo. Y él vive este modelo de gestión como una amenaza y eso le lleva a que en ese primer momento de sorpresa cuestione la demanda del jefe con algunas pegas reales y razonables, pero no con una aceptación incondicional que es lo que se esperaba de él. Por eso él presiente que el jefe se ha molestado. Pero yo intuyo que su respuesta ha estado mediatizada por esa primera impresión de miedo, de rabia, de contrariedad y de cierta postura de resistencia. Y, recordemos que $A$. desde el workshop ha hecho una conexión de este jefe con los modales de su profesor de inglés, y con la forma de comportarse su padre con él. Por eso creo que estamos en el principio de otro bucle y veo venir la dinámica cíclica, que realimenta la creencia de: yo soy inferior y el otro es autoritario y maltratador. Pienso que yo también estoy ante una situación de urgencia y me tendré que trasladar, ya mismo, a primera línea de guerra emocional. Asi que preparo mi arsenal de armamento: calma, comprensión, mentalización para ponerme en la situación de lo que le ocurre (S. Buechler). "Para mi el problema de este microconflicto o de otros que haya habido, es la reaccion que la otra persona pueda tener: que piense que no estoy cumpliendo, o que no estoy haciendo bien lo que tengo que hacer y así lo comunique a la dirección y me puedan echar. Ese es mi miedo de fondo en esos microconflictos". Y atención al añadido: "es muy fácil dar directrices desde arriba, qué poco piensan en lo que sufren los que están abajo". Es como decirme que le da miedo de que su interés en hacer las cosas un poco más democráticamente y no porque hay que obedecer ciegamente, sea interpretado de forma descalificadora de que no sirve, ni cumple y que es un narcisista que va a lo suyo (Bleichmar). Eso debía ser lo que le pasaba con el profesor de inglés y con su padre.

Por eso yo abordo la parte cíclica muy poco a poco co-creando nuevas alternativas y posibilidades y, dado que este tipo de personas le van a alterar siempre, que pueda redirigir ese primer pronto automático. Y voy viendo cómo le resuenan estas ideas, porque hemos de llegar a que comprenda paulatinamente, que lo que provoca reacciones adversas es que es brusco, molesto, incómodo. Pero habré de tener un especial cuidado de no herirle, como 
ocurría con el profesor de inglés, que le afeaba su mala conducta y le echaba, " $y$ yo nunca sabía como mejorar". O sea, como dice Wachtel seguir bidireccionalmente el núcleo de la esfera intrapsíquica que es el que genera conductas, y a la conducta que crea a la vez un esquema intrapsíquico. Y comenta: "Yo creo que necesito crear, canalizar, reaccionar de forma que pueda ganar tiempo y me ayude a bajar ese primer momento de reaccion visceral que tuve. Será un poco por la experiencia de gente que me he encontrado asi, pero tengo un fondo claro de alertas que son reales. Pero igual me equivoco". Es como decirme: de acuerdo, igual tengo que moderar mi primera reaccion airada, pero que no me vaya yo al otro extremo y me pase desapercibido que una parte de su mala actuación también la hay y a mi me provoca. De acuerdo, le digo: quizá haya que buscar estrategias cuando te pillan por asalto, para que no resultes molesto e incómodo.

Y quizá sea más práctico buscar otra manera de estar correctamente en el pupitre sin que te tengan que echar. "Si, es verdad, es más práctico darme cuenta del inicio del bucle. Eso en el workshop anterior y en este $2^{\circ}$ me ayudó mucho a controlar este tipo de reacciones.

Posteriormente fuimos analizando poco a poco entre los dos cómo fue su respuesta, que resultó ser que él contestó desde el enfado, desde la frustración, por la injusticia, sintiéndole dictatorial, y "el pánico, a encontrarme con el sitio nuevo, tener que partir de cero y crear estructuras nuevas, pensé que quizá no fuera capaz de hacer lo que me pedían y ahora veo que influido por ese miedo, en ese momento los argumentos que le di estaban desestructurados". Y le dije: es que cuando tu tienes pánico porque crees que no sabrás hacer lo que te piden, se te enciende la cólera y efectivamente, das argumentos desestructurados.

A.: si lo veo muy claro. Es muy práctico ver el inicio del bucle. Eso en el workshop me ayudó mucho a controlar este tipo de reacciones.

2.- Ha tenido que coordinar las labores de evacuación del personal, poner en sitio seguro a los compañeros y dejar bien a los que se tenían que quedar y cómo debían actuar. "Supimos por el monitoreo que hacemos, que el ejército estaba a diez minutos de nosotros. Ha sido muy interesante porque es la primera evacuación tan grande que he tenido que hacer y ha salido bastante bien". Le pregunto: ¿cómo te has quedado tu por dentro después de eso? "muy contento, respondió, estoy orgulloso de la contribución mía y lo bien enfocado que estuvo. Pensaré en las capacidades que tanto hablamos que tengo y cómo evitar que en los momentos en que no esté tan fuerte, que no me olvide que puedo hacerlo bien". Estamos mucho rato dando vueltas a eso, a ver qué siente, qué piensa de él mismo, como puede desarrollar una subjetividad nueva (Bleichmar)

3.- Le ha dicho la directora que quiere hablar con él al día siguiente. Dice: "Cuando me lo dijo yo apenas pude dormir pensando en que me iban a despedir, que no estaban contentos, que no 
respondía a las expectativas y me comunicarían que cerraban el contrato y ya está. Sabes mi estilo con esto. Denunciar por despido improcedente como hice en el otro trabajo y lo gané". Lo real fue que la reunión era para reconocer que había sido un error que le cambiaran de sitio, como él había dicho, y que era mejor que volviera a su lugar de origen. "Algo que en verdad era lo lógico yo lo convertí en que me querían echar. Eso siempre lo tengo ahí, es una inquietud que vivo de esa forma". Yo le digo cómo me impacta lo que me cuenta de lo mal que paso la noche, cómo percibo y valoro la gravedad de la situación, y la dificultad, la angustia y el peligro, y cómo admiro la manera de no quedar absorbido por el bloqueo y la dificultad para atender, y cómo es su día a día de angustia, de tensión, qué intensidad de emociones.

Es curioso que él acaba provocando lo que en realidad más teme y con ello se le confirma que el mundo es muy autoritario y muy agresivo. Y cuando él siente un mundo autoritario y agresivo no es únicamente una proyección de su infancia sino que al contrario, la sensibilidad que él adquirió en su infancia le permite sublevarse contra lo que tiene de agresivo y de autoritario el mundo que le rodea. Mucha atención con el tópico psicoanalítico de que todo lo que pasa son proyecciones de las cosas no resueltas que arrastramos de nuestro self arcaico. Siguiendo la idea de Wachtel no siempre él provoca esto. Si se encuentra con personas autoritarias, despóticas que le corrigen diciendo que es por su bien, lo cual no es cierto, hemos de pensar que el entorno existe antes de lo que uno provoca.

Nos preguntamos Ramón Riera y yo si la visión que él tiene es razonable o está distorsionada por el peso de su historia, por las experiencias de autoritarismo de su padre y del profesor de inglés. Por un lado tiene un radar que detecta a la gente autoritaria y manipuladora porque está muy entrenado en su vida, con lo cual esa experiencia traumática le es útil, le da un tipo de sensibilidad. Pero por otro lado como está traumatizado, ante ese tipo de jefes, reacciona de una forma demasiado brusca, virulenta, cae mal, y aparece como alguien incómodo. Y hemos hablado bastante de que a la hora de trabajar este concepto de los bucles de la dinámica cíclica, cómo las experiencias traumáticas no solo dejan secuelas negativas, sino que dejan también secuelas que son muy positivas, como es tener una sensibilidad que de otra manera no tendría. Nos ha parecido interesante tener esto en cuenta, porque quizá esto, en general, se tiene poco presente sobre todo en el psicoanálisis de la sospecha, buscando sólo lo que está estropeado y no viendo otra cosa.

Además da un dato interesante: "me he dado cuenta de que cuando me meto en el bucle tengo más dificultades con el inglés, y me pasa igual con la lectura, tengo que hacer un sobreesfuerzo de concentración que no es normal. La sensación que tengo en esos momentos es muy parecida a la que tenia en el colegio cuando tenía examen, o cuando el profesor me preguntaba alguna cosa o cuando veía que no era capaz de responder a una pregunta. Es como si se apagara el 
interruptor. Y me digo cómo es posible que ayer estaba con esta persona con una conversación fluida y hoy no me entero. En cambio, cuando tengo la terapia noto que a nivel mental me abro más a cosas que antes me resultaban muy complicadas, es como si se limpiase el camino y se conectase todo con más facilidad. Desde que trabajamos el tema del workshop ha bajado esa amenaza que siento, estoy más sociable y más integrado". Le digo que por primera vez no le han echado de la clase

\section{VIÑETA 6.- "SE ME COCIÓ POR DENTRO QUE ME CUESTIONARAN"}

"Te contaré un ejemplo de lo que me pasó en una organización. Tenía a mi cargo un equipo de unas 30 personas para llevar a cabo un proyecto que era de mucho dinero y en una situación muy complicada. Había muchos retos pero todo funcionó bien. Tenía aceptación y reconocimiento del equipo como buen jefe y eso me gustaba y me sentaba muy bien a nivel personal. Pero hubo un momento en que choqué con el escalón superior, los arquitectos, los ingenieros, les veía en plan chulito conmigo, en vez de reconocer el buen trabajo conseguido, cuchicheaban, lo cuestionaban, como si me miraran por encima del hombro, y a mi eso se me coció por dentro, asíque pensé: si vosotros pegáis un puñetazo en la mesa yo lo doy más grande. Y se generó un lío formidable y después de haber hecho un trabajo estupendo, me echaron. Fue una reacción visceral que yo no noté pero me hizo mucho daño. Me suele pasar cuando estoy con gente que siento superior a mi en estudios, ingenieros, arquitectos. Con ellos tengo más dificultades porque no logro construir una buena relación y me centro en competir con ellos y en cuestionar sus trabajos. Pienso que si ellos ponen sus capacidades intelectuales yo pongo mi experiencia y saco pecho, no me corto y tiro para adelante. Y eso me reporta problemas. Si no sale bien me queda la puerta abierta a crear un enemigo que pueda necesitar después. Controlar esa reaccion es lo que necesito trabajar. Creo que esta capacidad de reflexión de la que tu me hablas sería como limpiar ese fondo que tengo y que se asiente".

Una explicación a esta viñeta es que él en el trabajo quiere luchar contra situaciones que ve inadecuadas. Hasta ahí seria sano, significaría que él no se conforma con lo que viene dado, (Kohut ), ni se muestra pasivo para no meterse en líos. El es un luchador, que quizá aprendió luchando contra su padre o quizá más contra el profesor de inglés del colegio, tantas veces como se sintió vilipendiado por él. Eso le haría sublevarse contra la injusticia que es la vida. ¡Cuántas veces llora diciendo ¿por qué me tocó esto a mi? Es interesante esto porque no es que él sea alguien que tiene una tara, no es alguien que proyecta en los jefes los problemas con su padre, sino que él sabe que en el mundo hay mucha injusticia y no quiere cerrar los ojos ante ello. (Molet). Quizá en esto se identificó con la parte sana de su padre al que admiraba aunque era cruel con él. "Si esa es la parte que admiré de él, admiraba su trabajo, yo 
estaba orgulloso de su capacidad de tener muchos empleados y era un trabajador incansable, la consecuencia de eso es que no estaba en casa nunca y no nos dio esa visión de la vida".

Efectivamente él reconoce en su padre una parte trabajadora, esforzada, responsable. Ahora el padre está muy enfermo, se siente más vulnerable y se deja cuidar cariñosamente por A. que lo hace de forma extraordinariamente generosa. La pena es que esta parte emocional a A. no le llena, él busca reconocimiento con enorme sed. Intuye que su padre está orgulloso de él, pero eso, únicamente lo intuye, porque jamás se lo ha dicho ni es previsible que se lo diga. Es más, llegamos los dos a la conclusión de que, aunque su padre se lo expresara verbalmente él no le creería, como no se cree cuando le dice te quiero porque "decir te quiero suena como un ruido extraño en mi familia".

\section{REFERENCIAS}

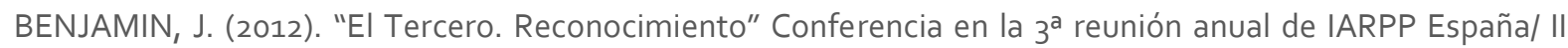
jornadas de psicoanálisis relacional. Sevilla

BLANCO, L y RIERA, R. (2016). El Proceso de Cambio en Psicoterapia Clínica e Investigación Relacional. CEIR. Vol. 10 (3)

BLEICHMAR, H. (2012). Conferencia dictada en la Sociedad Forum de Psicoterapia Psicoanalítica, sobre la regulación emocional. junio

BLEICHMAR, H. (2016). Colonizaciónemocional.com. Video 1: Cómo es vivir con una personalidad narcisista.

BLEICHMAR, H. El Enfoque Modular Transformacional y su ubicación dentro del panorama teórico del psicoanálisis actual. Artículo publicado en la Revista aperturaspsicoanaliticas.org n 43

BOWLBY, J. (1986). Vínculos afectivos: formación, desarrollo y pérdida. Madrid: Ed. Morata.

BUECHLER, S. (2008) Reseña del libro: Marcando la diferencia en la vida de los pacientes. Experiencia emocional en el ámbito terapéutico. Traducción: Alejandro Ávila, coordinador. Madrid: Ágora Relacional [2015]) Autora de la reseña: Lucía Blanco

BUECHLER, S. (2016). Poesía y creatividad psicoanalítica. Ponencia presentada en las Jornadas Internacionales de IARPP. Roma

DOCTORS, S.R. (2011). Liberando a los pacientes de los residuos de traumas relacionales: la búsqueda de Brandchaft. Clínica e Investigación Relacional, 5 (3): 517-523. [ISSN 1988-2939

GUERRA CID. L.R. (2013). El clavo ardiendo. Claves de las adicciones amorosas y los conflictos en las relaciones de pareja sanas y patológicas. Barcelona: Ed. Octaedro,.

KOHUT, H. (1996). Análisis del self. El tratamiento psicoanalítico de los trastornos narcisistas de la personalidad. Amorrortu editores.

KOHUT, H. (2009). Los dos análisis del Sr. Z. Barcelona: Ed. Herder.

MOLET, L. (2016). The pain is deaf. Art as pain transformation. Ponencia presentada en la Jornada Internacional de IARPP 2016 Rome, Italy.. The art of time. Relational psychoanalysis and forms of vitality in clinical process. 
NARANJO, R. (2008). Entrevista a Paul Wachtel. Clínica e investigación Relacional, 2008. Volumen 2 (2)

ORANGE, D. (2011). La actitud de los héroes: Bernard Brandchaft y la hermenéutica de la confianza. Clínica e Investigación Relacional, CEIR, 5 (3)

RIERA, R. (2011). La Conexión Emocional: cómo se forma nuestra manera espontanea y no voluntaria de reaccionar emocionalmente Barcelona: Octaedro,

STERN, D. (1997) La experiencia no formulada: de la disociación a la imaginación en psicoanálisis [Reseña hecha por Mónica de Celis. Publicado en Aperturas Psicoanalíticas n²1. 2005

VELASCO, R. (2015). Contextos de una psicoanalista. Conferencia dada en Ágora Relacional, y que forma parte del monográfico: Psychoanalysis in Spain que publicó la Revista Psychoanalytic Inquiry. № 35.

VELASCO, R. (2016). Transcripción del audio de una sesión clínica de revisión de pacientes, sobre la acomodación patológica. Barcelona, julio 2016.

VELASCO, R. y col. (2016). La interacción en análisis. Ponencia presentada en Roma en la Jornada Internacional de IARPP.

VYGOTSKY, L. (1978). La zona de desarrollo próximo. Pensamiento y lenguaje, Madrid: Paidós.

WACHTEL, P. (1996). La comunicación terapéutica. Principios y práctica eficaz. Bilbao: Desclée de Brower. Biblioteca de Psicología

WACHTEL, P. (2017). El mundo interno y el externo y su vinculación a través de la acción. Capítulo 3 del libro "Cyclical Psychodynamics and the Contextual Selfs". Traducción a cargo de Luisa Vilardell (Barcelona) 2017

WACHTEL, P. Las metáforas en psicoanálisis. La superficie y las profundidades. La metáfora de lo profundo en psicoanálisis y la manera en que puede llevar a conclusiones erróneas. Contemporary Psychoanalysis, Volumen 39, Número 1. Reseña hecha por Lidia Margulies, en la revista Aperturaspsicoanaliticas.org nº $\underline{014}$

WACHTEL, P. One-Person and Two-Person 2010. Conceptions of Attachment and their Implications for Psychoanalytic Thought

WACHTEL, P. Reseña: Teoría relacional y la práctica de la psicoterapia. 2008. Reseña de Alicia Fernández, publicada en la revista Aperturas Psicoanalíticas n031

WACHTEL. P. De lo bipersonal a lo contextual. Más allá de la infancia y de la consulta. Capítulo cuatro del libro "Relational Theory and the Practice of Psychotherapy". Traducción a cargo de Juan José Martínez (Sevilla). 2017

WACHTEL. P. (2008). Disociación, múltiples estados del self e intersubjetividad: psicodinámicas cíclicas y sus implicaciones para la práctica relacional. Clínica e investigación Relacional. Volumen 2 (2)

WALLIN, D. (2014). "Heridas que deben servir de herramientas: la historia de apego del terapeuta como fuente de impasse y de inspiración". Videoconferencia expuesta en Barcelona.

Original recibido con fecha: $\quad$ 28-4-2017 Revisado: $\quad 30-8-2017 \quad$ Aceptado: 30/09/2017 